\title{
'Wat jy ook op die aarde mag bind, sal in die hemel gebonde wees, en wat jy ook op die aarde mag ontbind, sal in die hemel ontbonde wees' (Matt 16:19)
}

\author{
Author: \\ Theuns F.J. Dreyer ${ }^{1}$ \\ Affiliation: \\ ${ }^{1}$ Reformed Theological \\ College, University of \\ Pretoria, South Africa \\ Correspondence to: \\ Theuns Dreyer \\ email: \\ theuns.dreyer@up.ac.za \\ Postal address: \\ Reformed Theological \\ College, Faculty of \\ Theology, University of \\ Pretoria, Lynnwood Road, \\ Hatfield 0083, Pretoria, \\ South Africa \\ Dates: \\ Received: 15 July 2010 \\ Accepted: 19 July 2010 \\ Published: 07 June 2011 \\ How to cite this article: \\ Dreyer, T.F.J., 2011, '”Wat \\ jy ook op die aarde mag \\ bind, sal in die hemel \\ gebonde wees, en wat \\ jy ook op die aarde mag \\ ontbind, sal in die hemel \\ ontbonde wees" (Matt \\ 16:19)', HTS Teologiese \\ Studies/Theological Studies \\ 67(1), Art. \#914, 4 pages. \\ DOI: $10.4102 /$ hts.v67i1.914
}

(C) 2011. The Authors. Licensee: OpenJournals Publishing. This work is licensed under the Creative Commons Attribution License.
'What you prohibit on earth will be prohibited in heaven, and what you permit on earth will be permitted in heaven' (Mt 16:19)

This article has been a homiletic reflection on the well-known words in Matthew 16:19. The explication and application of these words have been theologically contextualised with respect to current debates amongst theologians in the Nederduitsch Hervormde Kerk. The original meaning of this verse relates to the rabbinical tradition of interpretation of the Torah. Matthew pictures Jesus as the new teacher (like Moses), who gave a new interpretation of the law. In rabbinical language, his teachings are 'binding' and 'loosening', or, as translated in the Good News Bible (1933), they permit and prohibit. In the history of the reformed tradition, this verse was mostly interpreted from a judicial perspective as the authority to excommunicate or to include. To a great extent and especially in certain circles, the tradition of interpretation became static because of the authority of a 'final' interpretation attached to the creeds of the church. However, the original meaning of this verse is the authority, and commands us continuously to interpret the meaning of the gospel in the context of the present-day situation.

'n Uitnemende akademiese loopbaan van 'n gewaardeerde kollega en vriend, professor Andries van Aarde, is vanweë gesondheidsredes formeel beëindig. Soos ons hom ken, sal dit nie beteken dat hy sy navorsing en teologiese bydraes staak nie. Tog is dit ' $n$ punt van waar ' $n$ mens formeel kan terugkyk op sy formidabele bydrae tot die teologiese debat in Suid-Afrika sowel as internasionaal. Hy was nie slegs op sy vakgebied 'n kenner en navorser nie, maar was deur sy groot belesenheid ook ' $n$ meester op feitlik alle terreine en in alle dissiplines wat met die teologie verband hou. Om sy teologiese denke te verstaan was nie altyd maklik as jy dit bloot uit sy gepubliseerde navorsingsuitsette wou agterkom nie. In lang gesprekke moes jy ook eers die mens Andries van Aarde leer ken om sy eie worsteling met die teologie en sy persoonlike geloof te kon peil. Nog beter, jy moes hom hoor preek om te ervaar hoe hy moeilike teologiese kwessies so kon vertolk dat dit mense tot verwondering en 'n naïewe geloof kon begelei.

Nieteenstaande weerstand teen, en soms selfs verdagmakery oor, sy teologie, dikwels vanweë wanopvattings, het sy liefde vir en solidariteit met die Hervormde Kerk nooit gekwyn nie. Daarom dra ek graag hierdie openingsrede van die 69ste Algemene Kerkvergadering van die Nederduitsch Hervormde Kerk, gelewer op 26 September 2010, aan hom op. My uitgangspunt is die uitsprake van Jesus soos dit opgeteken is in Matteus 11:29-30 ('Neem my juk op julle en leer van My ... My juk is sag en my las is lig') en Matteus 16:19 ('... wat jy ook op die aarde mag bind, sal in die hemel gebonde wees en wat jy ook op die aarde mag ontbind, sal in die hemel ontbonde wees').

'Die Bybel sê so.' Dít is gewoonlik die argument wat ons gebruik om gesag aan ons standpunt te verleen. Soms hoor 'n mens dat iemand sê: 'Jy moet na ons kerk toe kom, want daar leer en preek ons dominee, of pastoor, nog die Bybel.' In sekere teologiese kringe is daar soms 'n nog hoër gesag. Jy beroep jou op die belydenisskrifte, want die belydenisskrifte sê wat die Bybel sê - dan kan daar geen twyfel oor jou standpunt wees nie. Indien dit so eenvoudig en reglynig is om jou op die Bybel te beroep, hoe is dit dan moontlik dat mense met teenoorstaande standpunte sê: 'Die Bybel sê so'?

Die antwoord is vanselfsprekend. As ek sê: 'Die Bybel sê so', sê ek eintlik dat dit my interpretasie, of verstaan, van die Bybel is. Alle Christelike denominasies waarvan ek weet, beroep hulle op die Bybel. Daardie kerk of groep waarheen jy moet gaan, waar die Bybel nog gepreek word, predik eintlik daardie dominee, of pastoor, se interpretasie van die Bybel. Die belydenisskrifte waarop ons ons beroep, is die interpretasie wat ' $n$ sinode in die verlede van die Bybel gegee het en wat die kerk as belydenisskrif aanvaar het. 
'So sê die Bybel' hou altyd verband met die interpretasie en vertolking van die Bybel. Vanaf die vroegste tye was mense besig met hierdie interpretasie. In die tyd van Jesus was dit by uitstek die skrifgeleerdes wat die Tora, of die wet van Moses, geïnterpreteer en uitgelê het. In die rabbynse tradisie was daar verskillende rabbi's of leermeesters, elk met hul eie kring dissipels of volgelinge, wat hul leermeesters se leer of vertolking van die Tora nagevolg het. Die antieke rabbi's het verstaan dat die Bybel oop is vir interpretasie. Hul rol in die gemeenskap was juis om die Tora te bestudeer, daaroor te mediteer, dit te bespreek, daaroor te bid, en dit dan vir die mense te interpreteer. Rabbi's het verskillende interpretasies van die Tora en hul eie stel reëls gehad wat nagevolg moes word. Hierdie reëls het iets gebind, of verbied, of andersins iets losgemaak, of toegelaat. 'n Rabbi se stel reëls en regulasies is die rabbi se 'juk' genoem. As jy daardie rabbi se leringe gevolg het, het jy sy juk op jou geneem en streng daarvolgens geleef. As 'n leerling 'n gedagte sou uitspreek wat volgens die rabbi die korrekte interpretasie was, sou hy vir die leerling sê: 'Jy het die wet volbring.' As 'n leerling egter 'n verkeerde interpretasie gemaak het, sou die rabbi gesê het: 'Jy het die wet ongeldig gemaak.'

Die meeste rabbi's het hul 'juk' van 'n ander, bekende rabbi as voorganger geleer. Hulle het dan in die naam van daardie rabbi geïnterpreteer en geleer. So was daar verskillende skole wat die leringe van 'n bekende rabbi uit die verlede aangehang en nagevolg het. Die bekendste van hierdie skole was Hillel en Shammai, wat soms teenoorstaande interpretasies van die Tora voorgehou het. Soms het daar 'n nuwe rabbi op die toneel verskyn wat met 'n nuwe interpretasie van die Tora vorendag gekom het. Die mense sou dadelik vra waar sy gesag vandaan kom. So 'n nuwe rabbi kon slegs met gesag praat as twee ander gesaghebbende rabbi's hom die hande opgelê het en verklaar het dat hy ook met gesag kon praat.

Die Evangelie van Matteus beskryf Jesus as die beloofde Messias, die Seun van die lewende God. Die byvoeging van 'die lewende' onderskei Matteus van Lukas en Markus. Hierdie presisering as die Seun van die 'lewende' God het 'n dinamiese konnotasie, en wil beklemtoon dat hierdie Messias ernstig opgeneem moet word. Hy is die nuwe Leermeester, of Rabbi, wat die mense kom leer wat die wet, of wil van God, beteken. Dít word bevestig deur Johannes die Doper, wat self ' $n$ bekende leermeester was. Hy wys daarop dat Jesus wat ná hom sou kom, sy meerdere is wat met gesag sal praat. Daarna word dit ' $n$ tweede keer bevestig met die doop van Jesus as 'n stem uit die hemel sê: 'Dit is my geliefde Seun.' 'n Joodse hoorder sou dadelik besef dat Jesus se gesag as Leermeester deur twee stemme bevestig is.

Die skrywer van Matteus beeld Jesus as die tweede, 'eintlike' Moses uit wat die wet van God ontvang het en interpreteer. Volgens die Fariseërs het Moses op Sinaiberg die wet ontvang, die Tora geïnterpreteer, en dit mondelings oorgelewer. Matteus wil dit stel dat Jesus die 'eintlike' Moses is. Hy toon duidelike ooreenkomste tussen Jesus en Moses aan. Jesus se geboorte gaan gepaard met die kindermoord van Herodes en die vlug na Egipte; Moses se geboorte val saam met die kindermoord van Farao en Moses se redding van die volk vanuit Egipte. Jesus word in die woestyn versoek en voorberei vir sy opdrag; Moses word ook in die woestyn geroep. In Matteus is daar vyf langerige preke van Jesus, soos die vyf boeke van Moses. Matteus 5:1 begin met die opmerking:

Toe Jesus die menigte mense sien, het Hy teen die berg opgegaan. Nadat Hy gaan sit het, het sy dissipels na Hom toe gekom, en Hy het hulle geleer ....

Dít sinspeel weer op Moses wat op Sinaiberg die wet van God ontvang het. Die tweede, 'eintlike' Moses het ook op die berg gaan sit om die mense die evangelie van die koninkryk van die hemel te leer. Soos die gebruik in daardie tyd was, het die rabbi wat geleer het, gesit. Vir ' $n$ rabbi om te sit het min of meer dieselfde gesag gedra as wat die dra van ' $n$ toga, die stilgebed by die preekstoel, en die preek vanaf die preekstoel vir ons simboliseer. Jesus het ook soos ' $n$ rabbi gaan sit en sy dissipels met gesag begin leer. Die nuwe Rabbi, of Leermeester, is dus nou aan die woord.

In die rabbynse tradisie het ' $n$ nuwe rabbi wat ' $n$ ander interpretasie gehad het, gewoonlik begin deur te sê: 'Julle het gehoor dat daar gesê is, maar ek sê vir julle ...'. In sy onderrig sê Jesus dat Hy nie gekom het om die wet of die profete ongeldig te maak nie, maar om hulle hul volle betekenis te laat kry (Matt 5:17). Daarna begin Hy om die wet opnuut te interpreteer. Telkens gebruik Hy die tipiese woorde van 'n nuwe rabbi: 'Julle het gehoor dat daar van die ou tyd af aan die mense gesê is .... Maar ek sê vir julle ...' (Matt 5:21-22, 27-28, 31-32, 33-34, 38-39, 43-44).

Hy leer sy volgelinge dat dit in die koninkryk van die hemel nie in die eerste plek oor die wettiese en letterlike interpretasie van die wet gaan nie, maar dat God na die innerlike gesindheid van die hart vra. Eintlik interpreteer Hy die wet vanuit die perspektief van die liefde - daarom kan jy nie in jou hart jou broer haat en vervloek, terwyl jy vroom jou offer na die altaar bring nie. Dit help nie dat jy jou daarop roem dat jy nie ' $n$ valse eed afgelê het, maar intussen is jou 'ja' nie betroubaar nie. Daarom moet jy jou vyand liefhê en vergewe, in plaas daarvan om vergelding te eis. Jesus se optrede en dade bevestig hierdie verstaan van die wil van God. Hy bemoei Hom met onreines, sondaars en tollenaars. Hy vergewe mense hul sondes; genees melaatses, kreupeles en blindes wat volgens die wettiese reëls van die Fariseërs onrein is en nie by God welkom sou wees nie. Hy nooi sulke mense om Hom te volg en só hierdie nuwe koninkryk van die hemel, en die goeie tyding - die evangelie - wat hierdie heerskappy impliseer, sigbaar te laat word.

In Matteus 11:28-30 nooi Jesus mense, almal wat uitgeput en oorlaai is, om na Hom te kom en by Hom rus te kry: 'Neem my juk op julle en leer van My ... My juk is sag en my las is lig.' Sy 'juk' verskil van die sware laste wat die skrifgeleerdes op mense gelaai het deur hulle te hiet en te gebied, te bind en te verbied. Sy juk is lig en sag, want Hy maak mense los; Hy vergewe en verwelkom mense, al verdien hulle dit nie. Hy bevestig hierdie 'losmaak' as Hy in die volgende hoofstuk 
op die Sabbatdag saam met die dissipels, toe hulle honger geword het, teen die 'binding' van die Fariseërs in van die koringare uitvryf en eet. In Matteus 23:4 word vertel dat Hy die Fariseërs verkwalik het: 'Hulle bind swaar en ondraaglike laste saam en sit dit op die mense se skouers ...'.

Teen hierdie agtergrond kan ons Jesus se verrassende opdrag aan Petrus in Matteus 16:19, en later aan al sy dissipels (Matt 18:18), beter verstaan:

... Wat jy ook op die aarde mag bind, sal in die hemel gebonde wees, en wat jy ook op die aarde mag ontbind, sal in die hemel ontbonde wees.

Hierdie gedeelte bevat talle ryk teologiese perspektiewe wat nie nou deurtastend bespreek kan word nie. Die episode speel af in Sesarea-Filippi, buite die heilige land, in die heidenwêreld, waar die keiserkultus hoogty gevier het. Hier is die tempels van verskeie gode. Hier is die rotsopening wat as die poorte van die doderyk en die woonplek van bose geeste beskou is. Juis hier moet Petrus die vraag beantwoord oor wie Jesus is. Hier spreek hy die belydenis uit: 'U is die Christus, die Seun van die lewende God' (Matt 16:16). Sy belydenis bevestig dít wat Matteus oor Jesus getuig. Jesus is die Messias, die Seun van die lewende God. Hy spreek met gesag; Petrus aanvaar dat dít wat Jesus hulle oor God en die koninkryk van die hemel geleer het, die vervulling is van die wet en die wil van God. Hierdie belydenis van Petrus is die begronding van die opdrag wat hy ontvang: '... Wat jy ook op die aarde mag bind, sal in die hemel gebonde wees, en wat jy ook op die aarde mag ontbind, sal in die hemel ontbonde wees.'

In die geskiedenis van die kerk en die teologie bestaan daar verskillende interpretasies van hierdie gedeelte. In die Rooms-Katolieke Kerk word die gedeelte gebruik om die gesag van die pous en sy sleutelmag te begrond. In die Reformatoriese teologie weer val die klem op Petrus se belydenis, en nie op sy persoon nie.

Ek wil egter fokus op die betekenis van die opdrag '... Wat jy ook op die aarde mag bind, sal in die hemel gebonde wees, en wat jy ook op die aarde mag ontbind, sal in die hemel ontbonde wees'. Hierdie 'bind' en 'losmaak' hou verband met die beeldspraak van 'toesluit' en 'oopsluit', wat op sy beurt teruggryp na Jesaja 22:22, waar die draer van die sleutels na die een verwys wat die gesag en mag het om die koning se huis oop en toe te sluit; die gesag en mag om mense toegang tot die koning - 'n oudiënsie of ontmoeting - te bied. Vir Matteus is Jesus die Messias van God wat toegang tot God moontlik maak. Jesus se volgelinge is soos aflosatlete wat die stokkie oorneem en moet toesien dat Jesus se evangelie vooruitgaan.

Die eintlike bedoeling van hierdie gedeelte is dat Petrus en die dissipels, wat volgelinge van Jesus geword en by Hom geleer het wat die wil van God - die evangelie - is, die opdrag ontvang om te interpreteer en te vertolk. Hulle moet op grond van dít wat hulle by Hom geleer het, in elke nuwe situasie 'losmaak' of 'bind'. Hulle moet mense leer wat die wil van God en die bedoeling van die koninkryk van die hemel inhou en beteken. Dit is derhalwe ' $n$ opdrag om voortdurend te interpreteer en te vertolk. Waar dít gebeur, breek die koninkryk van die hemel deur. Dit is ' $n$ eskatologiese moment. Dit is asof die grense tussen hemel en aarde, tyd en ewigheid, vervaag. Hierdie interpretasie, in navolging van Christus, geld ook in die hemel.

In die geskiedenis van die kerk is die gedeelte eerstens juridies geïnterpreteer. Dit gaan dus om die suiwer leer en die sleutelmag om deur die tug en die ban ketters van die koninkryk uit te sluit. Natuurlik is dít ook die uiteindelike gevolg van die interpretasie van 'bind' en 'losmaak', hoewel die primêre klem in so 'n interpretasie val op die verkondiging van die evangelie deur die kerk, met die verantwoordelikheid om te interpreteer en te vertolk. In Handelinge 15 vind ons 'n voorbeeld van die vroeë kerk wat by die kerkvergadering in Jerusalem nuut moes interpreteer. Daar was 'n nuwe situasie waaroor die kerk duidelikheid moes kry. Die vraag was in watter mate Christene uit die heidendom aan die Joodse Christene se vereistes oor besnydenis en reinheid moes voldoen. Deur gebed en onderlinge beredenering onder leiding van die Heilige Gees, het hulle tot 'n nuwe interpretasie gekom. Net so is die belydenisskrifte van die kerk die uitvloeisel van interpretasies in ' $n$ bepaalde situasie. Die Kerkhervorming is, in die lig van die evangelie van Jesus Christus, ook die gevolg van hernude interpretasie in ' $n$ bepaalde omstandigheid.

Elke Sondag wanneer ' $n$ dominee preek, is hy of sy besig om te interpreteer; om, in die lig van die evangelie en relevant vir ons tyd, te 'bind' en 'los te maak'. Ouderlinge en diakens voer die opdrag uit as hulle met mense oor hul geloofslewe praat. Ouers is besig om te interpreteer as hulle hul kinders leer onderskei tussen reg en verkeerd, goed en kwaad. Hierdie 69ste Algemene Kerkvergadering staan ook voor die opdrag om te interpreteer:

... Wat jy ook op die aarde mag bind, sal in die hemel gebonde wees, en wat jy ook op die aarde mag ontbind, sal in die hemel ontbonde wees.

(Matt 18:18)

Dit is ' $n$ groot verantwoordelikheid, omdat die besluite van hierdie vergadering lidmate sal rig in hul interpretasie van wat die evangelie van die Koninkryk van God, die wil van God, vir ons tyd behels.

Juis wanneer ons begin interpreteer, word verskillende interpretasies moontlik, wat baie kere tot onenigheid en selfs verdeeldheid lei. Ons vergeet egter dikwels dat ons ' $n$ gesamentlike akkoord het wat, as ons daarby bly, ons kan help om mekaar te vind. Die Bybel is ons oerbron, ons norm. Die interpretasie van die belydenisskrifte bied riglyne en kontoere vir ons verstaan daarvan. Ons teologiese tradisie en eietydse teologiese navorsing kan ons help om vir vandag, vir ons situasie, te 'bind' en 'los te maak'. Ons kan dít egter net doen as ons in geloof bely dat Jesus die Christus, die Seun van die lewende God, is. As ons waarlik sy volgelinge, sy dissipels, leerlinge van Jesus Christus is, sal ons ons deur sy 
verstaan van die wil van God en die koninkryk van die hemel laat lei. Ons kan dit net doen as ons lewe deur die misterie van God se liefde, vergifnis en genade bepaal word. Ons kan dit net doen as ons iets van Paulus se interpretasie verstaan dat ons sonder verdienste, net uit genade, deur geloof, gered word. Hierdie voortdurende opdrag om die Skrif te interpreteer is deel van ons Reformatoriese erfenis, want vir ons is die Bybel die 'normerende norm' [norma normans].

Op die agenda van ons vergadering is daar verskeie sake waaroor ons opnuut, in ons konteks, die Bybel sal moet interpreteer en vertolk, besluit, 'bind' en 'losmaak'. Die Bybel en die belydenisskrifte sê die kerk is een, maar hoe gaan die vergadering daardie eenheid in ons hedendaagse situasie interpreteer? Wat is die implikasie van die eenheid van die kerk vir ons deelname aan ekumeniese liggame? Die Bybel sê die kerk is daardie mense wat op grond van die kruisiging en opstanding van Jesus Christus deur God se Gees tot die geloof geroep is om deel van God se kerk te wees. Hoe gee ons egter vandag gestalte daaraan? Is die volkskerk 'n voorwaarde vir kerkwees of nie? Die Bybel sê intimiteit is 'n gawe van God wat ons in die verhouding tussen man en vrou moet koester, maar hoe gee ons gestalte daaraan in 'n samelewing waar egskeiding en saamwoon aan die orde van die dag is? Die Bybel sê alle mense is gelyk voor God, en dat ons nie teenoor ander mag diskrimineer nie. Watter gewig moet dít dra in ons besluite oor homoseksuele mense en ons apartheidsverlede? Die Bybel sê ons is God se gestuurdes in die wêreld om mense dissipels van Jesus Christus te maak. Tog krimp die kerk. Wat is fout? Hoekom sukkel ons dan so om reg te kry dat mense saam met ons dissipels van Jesus word? Dit is telkens nodig om weer te besin en te bedink hoe ons God se gestuurdes in die wêreld sal wees. Die Bybel sê ons moet die Woord verkondig en God aanbid en dien, maar hoe gee ons uitvoering daaraan in ' $n$ samelewing waar visuele, interaktiewe multimediakommunikasie die botoon voer?

In die lig van hierdie opdrag om in elke nuwe situasie weer te interpreteer en te vertolk, is dit te verstane waarom ons kerk nog altyd ten gunste van teologiese opleiding aan ' $n$ universiteit was. Om telkens nuut te probeer hoor wat die Bybel wil sê is dit nodig dat die antieke tekste kultuursensitief in hul eie konteks gelees word, en dat ons ons teologiese tradisie ken. Om vir ons dag te 'bind' en 'los te maak' vra ook dat ons ons vinger op die pols van ons tyd sal hê. Om te interpreteer, te verkondig, te besluit, bly ' $\mathrm{n}$ groot verantwoordelikheid en ' $n$ waagstuk.

'Neem my juk op julle en leer van My ... My juk is sag en my las is lig' (Matt 11:29-30).

... Wat jy ook op die aarde mag bind, sal in die hemel gebonde wees, en wat jy ook op die aarde mag ontbind, sal in die hemel ontbonde wees.

(Matt 18:18)

Dít geld ook vir hierdie Algemene Kerkvergadering. Mense in ons wêreld is moeg en uitgeput, moedeloos en getraumatiseerd. Hulle smag na rus. Hulle soek na antwoorde op hul vrae oor reg en verkeerd, goed en kwaad. Ons deins dikwels terug voor die verantwoordelikheid om in ons konteks, met ons eietydse vrae en uitdagings, opnuut te interpreteer. Dit is baie makliker om terug te gryp na die gemaksone van geykte interpretasies, want dan hoef ons nie die ongemaklike vrae te hanteer nie. Dit is egter hierdie vergadering se onontwykbare opdrag om, as dissipels van Jesus Christus, nuut te interpreteer.

'n Paar retoriese vrae wat elkeen self moet beantwoord, kan ons help om in hierdie vergadering met die regte gesindheid besluite te neem. Is jy nog bereid om, te midde van al die magte en kragte van ons tyd, saam met die kerk van alle eeue te bely dat Jesus die Christus, die Seun van die lewende God, is? Erken jy dat Hy ook Heer van jou lewe is? Het jy, as sy dissipel, waarlik by Hom geleer wat die liefde van God en die koninkryk van die hemel beteken? Het jy al in jou eie lewe sy nabyheid, liefde en vergifnis ervaar? Dan kan ons as vergadering dit waag om in geloof en gebed, onder leiding van die Heilige Gees, te 'bind' en 'los te maak'.

Onthou, Hy het gesê: 'Neem my juk op julle en leer van My ... My juk is sag en my las is lig.' As ons met die gesindheid wat daar in Jeus Christus was die opdrag uitvoer om te 'bind' en 'los te maak', sal daar ook in hierdie vergadering eskatologiese oomblikke wees waar die grense tussen hemel en aarde vervaag.

\section{Literatuurverwysings}

Bell, R., 2005, Velvet Elvis: Repainting the Christian faith, Zondervan, Grand Rapids. Bromley, G.W., 1974, Theological dictionary of the New Testament: Abridged in one volume, William B. Eerdmans, Grand Rapids.

Nolland, J., 2005, The New International Greek Testament Commentary: The Gospel of Matthew, William B. Eerdmans, Grand Rapids.

Van Zyl, H.C., 1987, 'Matteus 18:15-20: 'n Diachroniese en sinchroniese ondersoek met besondere verwysing na kerklike dissipline', DD-proefskrif, Universiteit van Pretoria. 